\title{
Atividade microbiana em solo do Semi-Árido sob cultivo de Atriplex nummularia
}

\author{
Sônia Valéria Pereira(1), Cosme Rafael Martinez ${ }^{(1)}$, Everaldo Rocha Porto(2), \\ Beatriz Regina Brito Oliveira( ${ }^{(3)}$ e Leonor Costa Maia( ${ }^{(4)}$
}

\begin{abstract}
(1)Instituto de Tecnologia de Pernambuco, Av. Prof. Luiz Freire, 700, Cidade Universitária, CEP 50740-540 Recife, PE. E-mail: svp@itep.br, cosme@lika.ufpe.br (2)Embrapa Semi-Árido, BR 428, Km 152, Zona Rural, CEP 56302-970 Petrolina, PE. E-mail: erporto@cpatsa.embrapa.br (3)Av. Bernardo Vieira de Melo, 2250, Piedade, CEP 54410-010 Jaboatão, PE. E-mail: beatriz@itep.br (4)Universidade Federal de Pernambuco, Dep. de Micologia, Av. Prof. Nelson Chaves, s/no, Cidade Universitária, CEP 50670-420 Recife, PE. E-mail: leonorcmaia@yahoo.com.br
\end{abstract}

\begin{abstract}
Resumo - Métodos para avaliar a atividade microbiana no solo são fundamentais no monitoramento ambiental de áreas degradadas. O objetivo deste trabalho foi investigar a atividade microbiana de solo do semi-árido cultivado com Atriplex nummularia Lindl. em áreas que receberam rejeito salino durante um e três anos, em comparação com um solo nativo, sem cultivo e não irrigada. $\mathrm{O}$ solo cultivado por três anos e que recebeu rejeito salino apresentou, no período seco, valores de $\mathrm{pH}, \mathrm{CE}$ e atividade de hidrólise do diacetato de fluoresceína (FDA) superiores aos das demais áreas. No entanto, foi observada correlação negativa entre o carbono microbiano e os valores do quociente metabólico $\left(\mathrm{qCO}_{2}\right)$. A biomassa microbiana e a fosfatase alcalina também foram superiores no solo cultivado por três anos e que recebeu rejeito salino em relação ao solo nativo sem irrigação, confirmando o desempenho de plantas halófitas na melhoria da qualidade do solo sob condições de estresse salino. O cultivo de A. nummularia constitui uma das alternativas para utilização de rejeito salino proveniente da dessalinização por osmose reversa.
\end{abstract}

Termos para indexação: emissão de $\mathrm{CO}_{2}$, biomassa microbiana, diacetato de fluoresceína, fosfatase alcalina.

\section{Microbial activity in a semiarid soil cultivated with Atriplex nummularia}

\begin{abstract}
Methods used to estimate the soil microbial activity are important to environmental monitoring of degraded areas. The objective of this research was to investigate the microbial activity of a semiarid soil cultivated with Atriplex nummularia Lindl. in a field receiving saline waste during one and three years, in comparison with an area without crop and irrigation. Soil cultivated during three years presented, during the dry season, values of $\mathrm{pH}, \mathrm{CE}$, and activity of FDA hydrolyses higher than those registered in other areas. However, a negative correlation between the microbial carbon and values of $\mathrm{qCO}_{2}$ was observed. The microbial biomass and the alkaline phosphates were also higher in the three years cultivated soil, in comparison with the native soil, non irrigated, confirming the role of halophytes for enhancing quality of soils under saline stress. Thus, the cultivation of A. nummularia is an alternative for using saline waste from the desalinization process.
\end{abstract}

Index terms: $\mathrm{CO}_{2}$ emission, microbial biomass, fluorescein diacetate, alkaline phosphatase.

\section{Introdução}

A escassez de água potável para consumo humano é um dos principais problemas para a sobrevivência das populações rurais nas regiões semi-áridas. A dessalinização de água via osmose inversa é uma alternativa de conversão de água salgada em água de boa qualidade, já consolidada em diversos países do mundo. No entanto, o uso indiscriminado de dessalinizadores e a falta de alternativas de manejo dos rejeitos salinos pode causar danos ambientais, acarretando contaminação dos mananciais subterrâneos e aumento da salinidade/ sodicidade do solo, afetando drasticamente a atividade microbiana nesses ambientes. A salinização do solo tem sido considerada um dos indicadores de degradação ambiental no Trópico Semi-Árido, ameaçando a sustentabilidade da agricultura irrigada na região Nordeste.

Embora as propriedades químicas e físicas do solo e seus efeitos no crescimento das plantas sejam intensamente investigados, apenas recentemente tem sido dada atenção aos aspectos envolvendo a atividade microbiana neste ambiente (Batra \& Manna, 1997). A biomassa microbiana é fundamental na transformação da matéria orgânica nos ciclos globais e no fluxo de energia, interagindo com as partículas do solo e participando de processos biológi- 
cos e bioquímicos essenciais para garantir a sustentação dos ecossistemas (Turco et al., 1994).

Parâmetros bioquímicos e biológicos são usados como índices de crescimento e de atividade microbiana no solo. Isoladamente, porém, não refletem os processos edáficos de forma aceitável, em razão da complexa dinâmica de crescimento e atividade dos microrganismos no solo. Em particular, a atividade enzimática no solo proporciona catálise de inúmeras reações necessárias ao ciclo de vida dos microrganismos, na decomposição de resíduos orgânicos durante o ciclo de nutrientes e na formação da matéria orgânica e estrutura do solo (Burns, 1978).

Métodos para estimar a atividade microbiana em solos da Região Semi-Árida são fundamentais no monitoramento ambiental e recuperação de áreas degradadas. Entre esses métodos se destacam a avaliação das atividades das fosfatases alcalinas e da hidrólise do diacetato de fluoresceína, da respiração do solo, da estimativa do carbono da biomassa microbiana e do quociente metabólico $\left(\mathrm{qCO}_{2}\right)$ (Garcia et al., 1994; Sarig \& Steinberger, 1994). A diversidade microbiana tem sido relacionada com a qualidade do solo; no entanto, estudos recentes apontam para a necessidade de investigação das interações e atividades metabólicas dos microrganismos nos processos ecológicos do solo (Taylor et al., 2002).

Para o aproveitamento do subproduto dos dessalinizadores, uma das alternativas propostas tem sido a irrigação de espécies halófitas, entre as quais se destacam as do gênero Atriplex (Porto et al., 2001). Além de bem adaptadas a solos áridos e salinos, estas plantas são capazes de tolerar condições climáticas adversas, sendo utilizadas em programas de reabilitação de solos em várias regiões áridas e semi-áridas em processo de degradação ou sujeitas à desertificação (Watson, 1990; Glenn et al., 1998). O cultivo de Atriplex pode ser uma alternativa viável para a região Nordeste, principalmente quando sua produção estiver atrelada à utilização dos rejeitos dos dessalinizadores de água salobra. $\mathrm{O}$ grande desafio é desenvolver e adaptar métodos para monitorar e avaliar o impacto do cultivo de halófitas sobre processos biológicos do solo.

O objetivo deste trabalho foi avaliar o efeito da irrigação com rejeito salino na atividade microbiana em solo do Semi-Árido sob cultivo de Atriplex nummularia Lindl.

\section{Material e Métodos}

O solo usado foi um Argissolo (Podzólico VermelhoAmarelo), textura arenosa (areia, 73\%; silte, 16\%; argi- la, 11\%), pH, 5,6; CE, 0,20 dS m${ }^{-1}$; matéria orgânica, $6,2 \mathrm{~g} \mathrm{dm}^{-3} ; \mathrm{P}, 4,7 \mathrm{mg} \mathrm{dm}^{-3}$; K, 0,33 $\mathrm{cmol}_{\mathrm{c}} \mathrm{dm}^{-3}$; $\mathrm{Ca}$, $1,16 \mathrm{cmol}_{\mathrm{c}} \mathrm{dm}^{-3} ; \mathrm{Mg}, 0,77 \mathrm{cmol}_{\mathrm{c}} \mathrm{dm}^{-3} ; \mathrm{Al}, 0,08 \mathrm{cmol}_{\mathrm{c}} \mathrm{dm}^{-3}$ e Na, $0,03 \mathrm{cmol}_{\mathrm{c}} \mathrm{dm}^{-3}$. O solo foi coletado no Campo Experimental de Manejo da Caatinga, Embrapa SemiÁrido, Petrolina, PE ( $9^{\circ} 4^{\prime} \mathrm{S}$ e $\left.40^{\circ} 20^{\prime} \mathrm{O}\right)$, com precipitação média anual de $569 \mathrm{~mm}$, evaporação potencial média anual de $2.680 \mathrm{~mm}$ e vegetação predominante de caatinga arbustiva arbórea. As análises físico-químicas do solo foram realizadas no Laboratório de Análise de Solo e de Plantas da Embrapa Semi-Árido, Petrolina, PE.

O rejeito salino utilizado na irrigação das plantas foi obtido do processo de dessalinização de água por osmose reversa, após utilização no cultivo de tilápia-rosa (Oreochromis sp.). A análise físico-química do rejeito (pH, 8,1; CE, 7.280 $\mu \mathrm{S} \mathrm{cm}^{-1}$; matéria orgânica, 42,3 g L-1; $\mathrm{P}, 1,25 \mathrm{mg} \mathrm{L}^{-1}$; $\mathrm{K}, 38 \mathrm{mg} \mathrm{L}^{-1}$; Ca, $303 \mathrm{mg} \mathrm{L}^{-1}$; $\mathrm{Mg}$, $372 \mathrm{mg} \mathrm{L}^{-1} ; \mathrm{Na}, 1.278 \mathrm{mg} \mathrm{L}^{-1} ; \mathrm{Cl}, 2.740 \mathrm{mg} \mathrm{L}^{-1} ; \mathrm{NO}_{3}{ }^{-}$, $2,4 \mathrm{mg} \mathrm{L}^{-1} ; \mathrm{NO}_{2}^{-}, 211 \mathrm{mg} \mathrm{L}^{-1}$ ) foi realizada no Laboratório de Química Ambiental do Instituto de Tecnologia de Pernambuco utilizando os métodos da American Public Health Association (1998).

Mudas de A. nummularia, provenientes de estacas, foram plantadas em uma área útil de $768 \mathrm{~m}^{2}$, sendo 16 plantas por bloco, em espaços de $4 \times 4 \mathrm{~m}$ e sistema de irrigação por sulcos. As coletas de solo foram realizadas em fileira, espaçadas entre si $2,5 \mathrm{~m}$, na profundidade de 0-15 cm, nos períodos seco (junho de 2001) e chuvoso (fevereiro de 2002). Foram coletadas sete amostras de solo (cada uma composta de três amostras simples) em cada uma das três áreas: uma testemunha, sem cultivo e não irrigada (Sistema I) e duas cultivadas com A. nummularia e irrigadas com rejeito salino por um ano (Sistema II) e três anos (Sistema III). As amostras não foram peneiradas para evitar que parte da microbiota ficasse retida durante o peneiramento. O delineamento experimental usado foi o inteiramente casualizado em arranjo fatorial $3 \times 2$, correspondendo a três sistemas (I, II e III) e dois períodos (seco e chuvoso). Foi determinada, em triplicata, a condutividade elétrica (solo: $\mathrm{H}_{2} \mathrm{O}, 1: 2$, após 24 horas de repouso), o teor de umidade a $105^{\circ} \mathrm{C}, \mathrm{o} \mathrm{pH}$ (solo: $\mathrm{H}_{2} \mathrm{O}, 1: 2$ ), o carbono orgânico, a biomassa microbiana, a respiração do solo e as atividades de fosfatase alcalina e de hidrólise de FDA.

O teor de carbono orgânico total foi determinado em $2 \mathrm{~g}$ de solo pelo método de oxidação com dicromato de potássio e posterior titulação com sulfato ferroso amoniacal (Tedesco et al., 1995). 
O carbono da biomassa microbiana foi determinado segundo Vance et al. (1987). Amostras de $25 \mathrm{~g}$ de solo, com capacidade de campo ajustada a $50 \%$, foram submetidas à atmosfera com clorofórmio livre de etanol por 24 horas, em temperatura ambiente $\left(25-28^{\circ} \mathrm{C}\right)$. Após a liberação dos vapores de clorofórmio, as amostras foram transferidas para Erlenmeyers nos quais adicionaram-se $100 \mathrm{~mL}$ de solução aquosa de $\mathrm{K}_{2} \mathrm{SO}_{4} 0,5 \mathrm{M}$. Os extratos obtidos após agitação $(150 \mathrm{rpm}, 30 \mathrm{minu}-$ tos) e filtração (Whatman no1) das amostras foram armazenados a $-20^{\circ} \mathrm{C}$, até o momento da análise do carbono microbiano. $\mathrm{O}$ mesmo procedimento foi adotado nas amostras não fumigadas. A determinação do carbono da biomassa microbiana foi realizada pelo método de oxidação com dicromato de potássio após digestão ácida a $100^{\circ} \mathrm{C}$ e posterior titulação com sulfato ferroso amoniacal, utilizando ferroína como indicador.

A respirometria do solo foi avaliada segundo Grisi (1997). Amostras com $100 \mathrm{~g}$ de solo, depois de ajustadas a $50 \%$ da capacidade de campo, foram mantidas em frascos de vidro hermeticamente fechados, contendo um recipiente com $10 \mathrm{~mL}$ de KOH 0,5N. Após incubação $\left(25 \pm 2^{\circ} \mathrm{C}\right)$ por 21 dias, o $\mathrm{CO}_{2}$ absorvido foi determinado por titulação com HCL $0,1 \mathrm{~N}$, usando-se fenolftaleína e metilorange como indicadores. Os valores de $\mathrm{CO}_{2}$ acumulados foram expressos em $\mu \mathrm{g}$ de $\mathrm{C}$ por $\mathrm{g}$ de solo seco. O quociente metabólico $\left(\mathrm{qCO}_{2}\right)$, que é o quociente entre a respiração do solo e a biomassa microbiana, foi calculado de acordo com Anderson \& Domsch (1978).

A atividade da fosfatase alcalina foi estimada conforme Eivazi \& Tabatabai (1977). Em amostras de $2 \mathrm{~g}$ de solo foram adicionados $8 \mathrm{~mL}$ de tampão MUB pH 11 e $2 \mathrm{~mL}$ de p-nitrofenilfosfato (p-npp) 0,025 M. Após incubação $\left(37^{\circ} \mathrm{C}, 1\right.$ hora) foram adicionados $2,0 \mathrm{~mL}$ de $\mathrm{CaCl}_{2}$ 0,5 $\mathrm{M}$ e $8,0 \mathrm{~mL}$ de $\mathrm{NaOH} 0,5 \mathrm{M}$ às suspensões de solo, que foram filtradas (Whatman $\mathrm{n}-1$ ) em seguida. Nos controles, a solução de p-npp $0,025 \mathrm{M}$ foi acrescentada após a adição de $2,0 \mathrm{~mL}$ de $\mathrm{CaCl}_{2} 0,5 \mathrm{M} \mathrm{e}$ $8,0 \mathrm{~mL}$ de $\mathrm{NaOH}$ 0,5 M. A leitura da absorbância foi realizada em $400 \mathrm{~nm}$. A curva padrão foi determinada a partir de uma solução estoque de $1.000 \mathrm{mg} \mathrm{L}^{-1}$ de p-nitrofenol, seguindo o mesmo procedimento adotado em relação às amostras. Os resultados foram expressos em $\mu \mathrm{g}$ de $\mathrm{p}$-nitrofenol por $\mathrm{g}$ de solo seco, por hora.

A atividade hidrolítica do FDA foi estimada segundo Swisher \& Carroll (1980). Amostras de $5 \mathrm{~g}$ de solo foram transferidas para Erlenmeyer $(250 \mathrm{~mL})$, juntamente com $20 \mathrm{~mL}$ de tampão fosfato de potássio $\mathrm{pH}$ 7,6 e
0,2 mL de solução estoque de FDA $\left(2 \mathrm{mg} \mathrm{mL}^{-1}\right.$ acetona). Após incubação $\left(25^{\circ} \mathrm{C}, 20\right.$ minutos $)$ sob agitação $(150 \mathrm{rpm})$, a reação foi interrompida pela adição de $20 \mathrm{~mL}$ de acetona. As suspensões de solo foram filtradas (Whatman no 1 ) e a leitura realizada em espectrofotômetro a $490 \mathrm{~nm}$. A curva padrão foi obtida adicionando-se alíquotas de FDA nas quantidades de 0-400 $\mu \mathrm{g}$ em 5,0 mL de tampão fosfato. Os tubos foram pré-hidrolisados em água fervente por $60 \mathrm{~min}$ e transferidos para Erlenmeyers contendo 5,0 g de solo e $15 \mathrm{~mL}$ de tampão fosfato. Os resultados foram expressos em $\mu \mathrm{g}$ de fluoresceína por $\mathrm{g}$ de solo seco, por hora.

Os dados foram submetidos à análise de variância pelo programa Statistica (Statsoft Inc.) e os efeitos dos tratamentos avaliados pelo teste $\mathrm{F}$ a $5 \%$ de probabilidade; as médias foram comparadas pelo teste de Tukey a $5 \%$ de probabilidade.

\section{Resultados e Discussão}

A análise de variância indicou interação entre os sistemas estudados e períodos de coleta para a condutividade elétrica (CE), $\mathrm{pH}, \mathrm{qCO}_{2}$, FDA e $\mathrm{C}$ total. A maior condutividade elétrica $\left(3,1 \mathrm{dS} \mathrm{m}^{-1}\right)$ foi observada na área cultivada há três anos com Atriplex no período seco (Tabela 1). No período chuvoso não houve diferença entre os tratamentos, indicando que a irrigação com rejeito salino, neste período, não alterou significativamente a $\mathrm{CE}$ do solo cultivado com $A$. nummularia.

Os valores de $\mathrm{pH}$ foram mais elevados no solo cultivado com Atriplex por três anos tanto no período seco quanto no chuvoso (Tabela 1). O aumento de $\mathrm{pH}$ observado nessa área, em relação ao cultivo por um ano, ocorreu provavelmente por causa do acúmulo de íons no solo com rejeito salino.

A evolução do $\mathrm{CO}_{2}$ do solo cultivado por três anos foi superior ao cultivado por um ano, não diferindo, ambos, do observado na área nativa (Figura 1). No entanto, nesta área o coeficiente metabólico $\left(\mathrm{qCO}_{2}\right)$ foi superior ao do solo das áreas cultivadas em ambos os períodos (Tabela 1), indicando que a biomassa microbiana na área sem cultivo possui maior atividade metabólica do que nas áreas cultivadas. Foi observada correlação negativa $(\mathrm{r}=-0,68)$ entre o $\mathrm{qCO}_{2}$ e o $\mathrm{C}$ microbiano. Garcia et al. (1994) avaliaram a atividade enzimática e microbiana em região semi-árida da Espanha, caracterizada por baixos conteúdos de carbono orgânico e de nutrientes disponíveis, encontrando correlação negativa $(\mathrm{r}=-0,50)$ entre o $\mathrm{qCO}_{2} \mathrm{e}$ outros indicadores de ativida- 
de microbiana como a biomassa microbiana e desidrogenase. Sarig \& Steinberger (1994) também observaram correlação negativa $(\mathrm{r}=-0,51)$ entre o $\mathrm{qCO}_{2}$ e a concentração de biomassa microbiana em solos cultivados com halófitas, sugerindo que a utilização de substratos disponíveis ao metabolismo e o investimento microbiano em energia para superar o estresse temporário, podem ter acarretado o fenômeno. Essas semelhanças foram demonstradas por Anderson \& Domsch (1978), em estudos da comunidade microbiana do solo sob várias culturas vegetais. Wardle \& Ghani (1995) verificaram que o cultivo não resultou em aumento significativo do $\mathrm{qCO}_{2}$, sugerindo redução na eficiência do uso de carbono pela comunidade microbiana do solo. Segundo esses autores, o aumento do $\mathrm{qCO}_{2}$ diante de perturbações no ecossistema do solo indica uma resposta da microbiota do solo às condições adversas.

Os teores estimados de carbono microbiano nas áreas cultivadas diferiram entre si, sendo mais elevado no sistema III, e foram superiores ao observado no sistema I (Figura 1). Esse fenômeno também foi observado por Sarig \& Steinberger (1994), em estudos com solo da região desértica de Israel cultivado com as plantas halófitas Zygophyllum dumosum e Reaumuria negevensis. Gupta \& Singh (1981) sugerem que a capacidade produtiva de solos alcalinos aumenta em razão do crescimento de plantas adaptadas à condição de estresse.

Os valores referentes à atividade da fosfatase alcalina foram superiores nas áreas cultivadas em relação aos da área testemunha, 23 e $4 \mu \mathrm{g}$ de p-nitrofenol por $\mathrm{g}$ de solo seco, respectivamente. Essa alteração na atividade enzimática pode ter sido ocasionada pelo aumento da biomassa microbiana observado nessas áreas. Garcia et al. (1994) verificaram altos valores de fosfatase em solo cultivado com Quercus rotundifolia, sugerindo que a vegetação atua na atividade da fosfatase alcalina no solo. A ação catalítica desta enzima requer $\mathrm{pH}$ na faixa alcalina, como o observado nas áreas cultivadas com
Atriplex, o que possivelmente favoreceu a detecção. Segundo Herbien \& Neal (1990), o pH do solo pode influenciar a síntese e a liberação das enzimas pelos microrganismos bem como a estabilidade e a conformação dessas substâncias. Frankenberger Junior \& Dick (1983) avaliaram 11 enzimas em 10 solos e constataram que a fosfatase alcalina, entre outras, esteve altamente correlacionada com a respiração e a biomassa microbiana no solo, mas não apresentou correlação com a contagem de células.

Estudos têm mostrado a necessidade de relacionar a atividade enzimática com a microbiologia do solo de uma forma mais específica. Medidas como emissão de $\mathrm{CO}_{2}$ e contagem de células viáveis, isoladamente, não refletem a atividade biológica do solo (Dick, 1997). No caso da respiração, os microrganismos podem não ser a única fonte de emissão de $\mathrm{CO}_{2}$ e a contagem microbiana não estima a atividade metabólica dos microrganismos isolados.

Com relação à atividade de hidrólise do FDA, nas áreas cultivadas, verificou-se maior atividade nos períodos secos (Tabela 1). No período úmido, os valores não diferiram do registrado no solo não cultivado, em ambas as áreas. A hidrólise do FDA não pode ser considerada um parâmetro específico da atividade enzimática de bactérias e fungos no solo, pois essa reação também pode ser catalisada por outros organismos como algas e protozoários. A atividade hidrolítica do FDA é usada como indicador geral da atividade hidrolítica do solo, como medida da protease, lipase e esterase que são capazes de clivar compostos fluorogênicos (Taylor et al., 2002). Desta forma, essa ação catalítica pode ser considerada uma medida da atividade microbiana total, embora as enzimas envolvidas nesta reação apresentem atividade externa à célula, podendo se encontrar complexadas com os colóides do solo (Swisher \& Carroll, 1980).

A avaliação do carbono total não revelou diferenças entre os solos nativo e cultivado nos períodos seco e chuvoso, mas foi constatada interação entre os siste-

Tabela 1. Valores médios da condutividade elétrica (CE), pH, atividade de hidrólise do diacetato de fluoresceína (FDA), quociente metabólico $\left(\mathrm{qCO}_{2}\right)$ e carbono total ( $\mathrm{C}$ total) em solos sem cultivo e sem irrigação (sistema I); solo com cultivo de Atriplex nummularia irrigada com rejeito salino por um ano (sistema II) e três anos (sistema III), nos períodos seco (S) e chuvoso (C) ${ }^{(1)}$.

\begin{tabular}{|c|c|c|c|c|c|c|c|c|c|c|}
\hline \multirow[t]{2}{*}{ Sistema } & \multicolumn{2}{|c|}{$\mathrm{CE}\left(\mathrm{dS} \mathrm{m} \mathrm{m}^{-1}\right)$} & \multicolumn{2}{|c|}{$\mathrm{pH}(1: 2)$} & \multicolumn{2}{|c|}{$\operatorname{FDA}\left(\mu g g^{-1} h^{-1}\right)$} & \multicolumn{2}{|c|}{$\mathrm{qCO}_{2}$} & \multicolumn{2}{|c|}{$\mathrm{C}$ total $\left(\mathrm{g} \mathrm{dm}^{-3}\right)$} \\
\hline & $S$ & $\mathrm{C}$ & $S$ & $\mathrm{C}$ & $S$ & $\mathrm{C}$ & $S$ & $\mathrm{C}$ & $S$ & $\mathrm{C}$ \\
\hline I & $0,546 \mathrm{aA}$ & $0,434 \mathrm{aA}$ & $5,97 \mathrm{aB}$ & $5,80 \mathrm{aA}$ & $14,31 \mathrm{aA}$ & $10,43 \mathrm{aA}$ & $271,7 \mathrm{aB}$ & $371,9 \mathrm{aC}$ & $5,23 \mathrm{aB}$ & $5,37 \mathrm{aB}$ \\
\hline II & $1,657 \mathrm{aA}$ & $0,557 \mathrm{aA}$ & $5,37 \mathrm{aA}$ & $6,83 \mathrm{aB}$ & $48,14 \mathrm{bB}$ & $15,86 \mathrm{aB}$ & $125,1 \mathrm{bA}$ & $44,2 \mathrm{aA}$ & $4,31 \mathrm{aA}$ & $5,74 \mathrm{aB}$ \\
\hline III & $3,100 \mathrm{bB}$ & $1,114 \mathrm{aA}$ & $6,96 \mathrm{aC}$ & $7,27 \mathrm{aC}$ & $49,57 \mathrm{bB}$ & $10,01 \mathrm{aA}$ & $102,9 \mathrm{aA}$ & $106,6 \mathrm{aB}$ & $5,60 \mathrm{aB}$ & $4,37 \mathrm{aB}$ \\
\hline
\end{tabular}

${ }^{(1)}$ Médias seguidas da mesma letra, minúscula na linha e maiúscula na coluna, não diferem entre si pelo teste de Tukey a 5\% de probabilidade. 
mas e o período de coleta. Diferenças no $\mathrm{C}$ total foram observadas apenas no período seco, tendo o solo do sistema II apresentado menores valores que os dos demais sistemas (Tabela 1). Dick (1994) observou que solos submetidos a sistemas de cultivo não apresentaram alteração mensurável no conteúdo de carbono total apesar do efeito significativo verificado na atividade da $\beta$-glucosidase. Chander \& Brookes (1991) afirmaram que a biomassa microbiana, atividade enzimática e a respiração do solo respondem mais rapidamente a alterações ambientais do que a matéria orgânica no solo. Segundo Garcia et al. (1994), o baixo teor de matéria orgânica é a principal causa da pouca atividade microbiana em solos de regiões semi-áridas.

A presença de vegetais é um importante fator na qualidade do solo, pelo fornecimento de fontes de energia necessárias à manutenção da população microbiana no solo (Pascual et al., 2000). Kramer \& Green (2000) atribuíram maior atividade da fosfatase em solo cultivado com Juniperus monosperma em relação ao cultivo de Hilaria jamessi, ao aumento da população fúngica sob essas árvores. Speir \& Ross (1978) consideram que a mudança na fosfatase decorre, provavelmente, do aumento do número de microrganismos, do crescimento de espécies vegetais e do incremento concomitante da

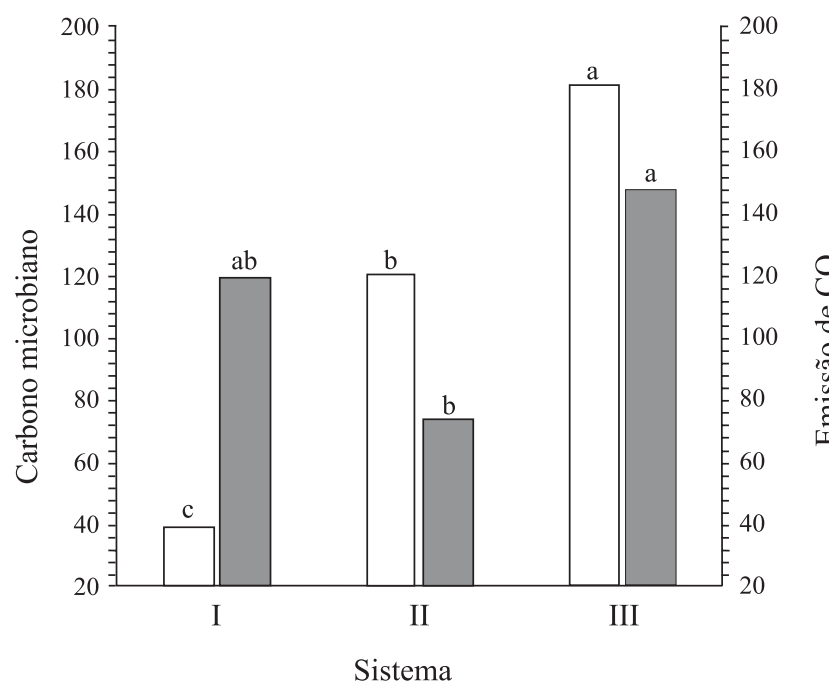

Figura 1. Carbono microbiano ( $\mu$ g por g de solo seco) ( $\square$ ) e emissão de $\mathrm{CO}_{2}$ ( $\mu \mathrm{g}$ de $\mathrm{C}$ por g de solo seco) ( $\square$ ) do solo nativo (sistema I) e dos solos cultivados por um ano (sistema II) e por três anos (sistema III) com Atriplex nummularia irrigada com rejeito salino. Médias com as mesmas letras não diferem entre si pelo teste de Tukey a $5 \%$ de probabilidade. matéria orgânica e do nível geral de enzimas no solo. Desta forma, modificações na microbiota do solo, atribuídas a fatores ambientais, podem ser refletidas no nível de atividade enzimática no solo.

A continuidade de estudos sobre a atividade microbiana nesses solos impactados é necessária para melhor entendimento dos processos e confirmação das tendências aqui observadas.

\section{Conclusões}

1. A biomassa microbiana, a fosfatase alcalina e a hidrólise do diacetato de fluoresceína podem ser usadas como características indicativas de alterações na atividade microbiana em solos do Semi-Árido sob cultivo de Atriplex nummularia.

2. A atividade microbiana de solos irrigados com rejeito salino é estimulada pelo plantio de Atriplex nummularia.

3. Atriplex nummularia constitui uma das alternativas no manejo integrado em solos salinizados do SemiÁrido.

\section{Referências}

AMERICAN PUBLIC HEALTH ASSOCIATION (Washington, DC). Standard methods for the examination of water and wastewater. 20th ed. Washington, 1998. 1220p.

ANDERSON, J.P.E.; DOMSCH, K.H. A physiological method for the quantitative measurement of microbial biomass in soils. Soil Biology and Biochemistry, v.10, p.215-221, 1978.

BATRA, L.; MANNA, M.C. Dehydrogenase activity and microbial biomass carbon in salt-affected soils of semiarid and arid regions. Arid Soil and Rehabilitation, v.11, p.295-303, 1997.

BURNS, R.G. Soil enzymes. New York: Academic Press, 1978. $379 \mathrm{p}$.

CHANDER, K.; BROOKES, P.C. Effects of heavy metals from past applications of sewage sludge on microbial biomass and organic matter accumulation in a sandy loam and a silt loam UK soil. Soil Biology and Biochemistry, v.23, p.927-932, 1991.

DICK, R.P. Soil enzyme activities indicators of soil quality. In: DORAN, J.W.; COLEMAN, D.C.; BEZDICEK, D.F.; STEWART, B.A. (Ed.). Defining soil quality for a sustainable environment. Madison: Soil Science Society of America, 1994. p.107-124. (SSSA Special Publication, 35).

DICK, R.P. Soil enzyme activities as integrative indicators of soil health. In: PANKHHURST, B.M.; DOUBE, B.M.; GUPTA, V.V.S.R. (Ed.). Biological indicators of soil health. Wallingford Oxon, UK: CAB International, 1997. v.6, p.121-156,

EIVAZI, F.; TABATABAI, M.A. Phosphatases in soils. Soil Biology and Biochemistry, v.9, p.167-172, 1977. 
FRANKENBERGER JUNIOR, W.T.; DICK, W.A. Relations between enzyme activities and microbial growth and activity indices in soil. Soil Science Society of American Journal, v.47, p.945-951, 1983.

GARCIA, C.; HERNANDEZ, T.; COSTA, F. Microbial activity soils under Mediterranean environmental conditions. Soil Biology and Biochemistry, v.26, p.1185-1191, 1994.

GLENN, E.; TANNER, R.; MIYAMOTO, S.; FITZSIMMONS, K.; BOYER, J. Water use, productivity and forage quality of the halophyte Atriplex nummularia grown on saline waste water in a desert environment. Journal of Arid Environments, v.38, p.45-62, 1998.

GRISI, B.M. Temperature increase and its effect on microbial biomass and activity of tropical and temperate soils. Revista de Microbiologia, v.28, p.5-10, 1997.

GUPTA, S.R.; SINGH, J.S. Soil respiration in a tropical grassland. Soil Biology and Biochemistry, v.13, p.261-268, 1981.

HERBIEN, S.A.; NEAL, J.L. Soil pH and phosphatase activity. Communications in Soil Science and Plant Analysis, v.21, p.439456, 1990.

KRÄMER, S.; GREEN. D.M. Acid and alkaline phosphatase dynamics and their relationship to soil microclimate in a semiarid woodland. Soil Biology and Biochemistry, v.32, p.179-188, 2000.

PASCUAL, J.A.; GARCIA, C.; HERNANDEZ, T.; MORENO, J.L.; ROS, M. Soil microbial activity as a biomarker of degradation and remediation process. Soil Biology and Biochemistry, v.32, p.1877-1883, 2000.

PORTO, E.R.; AMORIM, M.C.C.; SILVA JUNIOR, L.G.I.A. Uso do rejeito da dessalinização de água salobra para irrigação da erva-sal (Atriplex nummularia). Revista Brasileira de Engenharia Agrícola e Ambiental, v.5, p.111-114, 2001.
SARIG, S.; STEINBERGER, Y. Microbial biomass response to seasonal fluctuation in soil salinity under the canopy of desert halophytes. Soil Biology and Biochemistry, v.26, p.1405-1408, 1994.

SPEIR, T.W.; ROSS, D.J. Soil phosphatase and sulphatase. In: BURNS, R.G. (Ed.). Soil Enzymes. London: Academic Press, 1978. p.197-250.

SWISHER, R.; CARROLL, C.G. Fluorescein diacetate hydrolysis as an estimator of microbial biomass on coniferous needle surface. Microbial Ecology, v.6, p.217-226, 1980.

TAYLOR, J.P.; WILSON, B.; MILLS, M.S.; BURNS, R.G. Comparison of microbial numbers and enzymatic activities in surface soils and subsoils using various techniques. Soil Biology and Biochemistry, v.34, p.387-401, 2002.

TEDESCO, M.J.; GIANELLO, C.; BISSANI, C.A.; BOHNEN, H.; VOLKWEISS, S.J. Análises de solo, plantas e outros materiais. 2.ed. Porto Alegre: Faculdade de Agronomia, UFRGS, 1995. 174p. (Boletim Técnico, 5).

TURCO, R.F.; KENNEDY, A.C.; JAWSON, M.D. Microbial indicators of soil quality. In: DORAN, J.W.; COLEMAN, D.C.; BEZDICEK, D.F.; STEWART, B.A. (Ed.). Defining soil quality for a sustainable environment. Madison, WI: Soil Science Society of America, 1994. p.73-89. (SSSA Special Publication, 35).

VANCE, E.D.; BROOKES, P.C.; JENKINSON, D.S. An extraction method for measuring soil microbial biomass C. Soil Biology and Biochemistry, v.19, p.703-707, 1987.

WARDLE, D.A.; GHANI, A. Why is the strength of relationships between pairs of methods for estimating soil microbial biomass often so variable? Soil Biology and Biochemistry, v.27, p.821-828, 1995.

WATSON, C.M. Atriplex species as irrigated forage crops. Agriculture, Ecosystems and Environment, v.32, p.107-118, 1990.

Recebido em 7 de novembro de 2003 e aprovado em 11 de maio de 2004 